\section{Gingiva and enamel shades for greater individuality}

Whether distinct mucolabial folds, poorly vascularised areas or missing papillae: red aesthetics are becoming more and more important in restorative dentistry. To make gingiva reproduction with composites even more
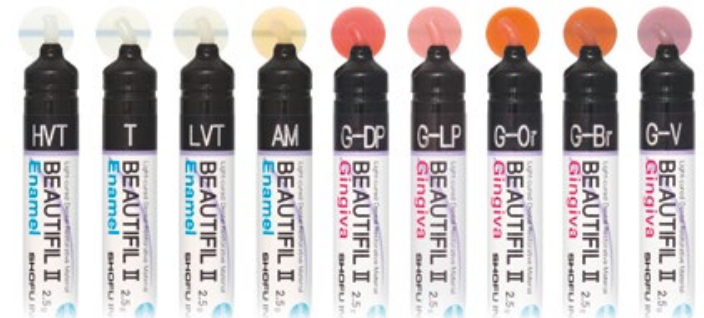

lifelike and individual, SHOFU has added high-quality Gingiva shades to the proven Beautifil II System - for a harmonious interplay between red and white aesthetics.

Five Gingiva shades, which can be blended and layered with each other, allow the reproduction of true-to-nature soft tissue areas with great depth and invisible transitions to the tooth. They are indicated primarily in cases of gingival recession, exposed abutments and crown margins, root erosion and missing papillae, and perfectly suited for Class $\mathrm{V}$ and other restorations. These pasty, non-sticky composites feature superior handling and sculpting properties and can easily and efficiently be polished to a high gloss.

The Enamel shades can also be blended and layered with each other, for unlimited possibilities in aesthetic anterior restorations. The four shades - Translucent, High-Value Translucent, Low-Value Translucent and Amber - allow to easily and efficiently create polychromatic restorations and invisibly repair restorations and dentures. Thanks to their excellent spreadability and sculptability, even fine details of the tooth morphology can be reproduced without difficulty.

For further information contact Shofu UK on 01732783580 or sales@shofu. co.uk.

\title{
Look, touch, feel and play
}

It is important for all members of the dental team to broaden their skills and scope of practice by attending industry events such as this year's BDIA Dental Showcase (17-19 October 2019, Birmingham NEC).

There are over 300 exhibitors attending. There will be plenty to peruse, and every possible individual interest and specialty will be catered for. You'll be able to really grill the trade on the latest innovation and look, touch, feel,

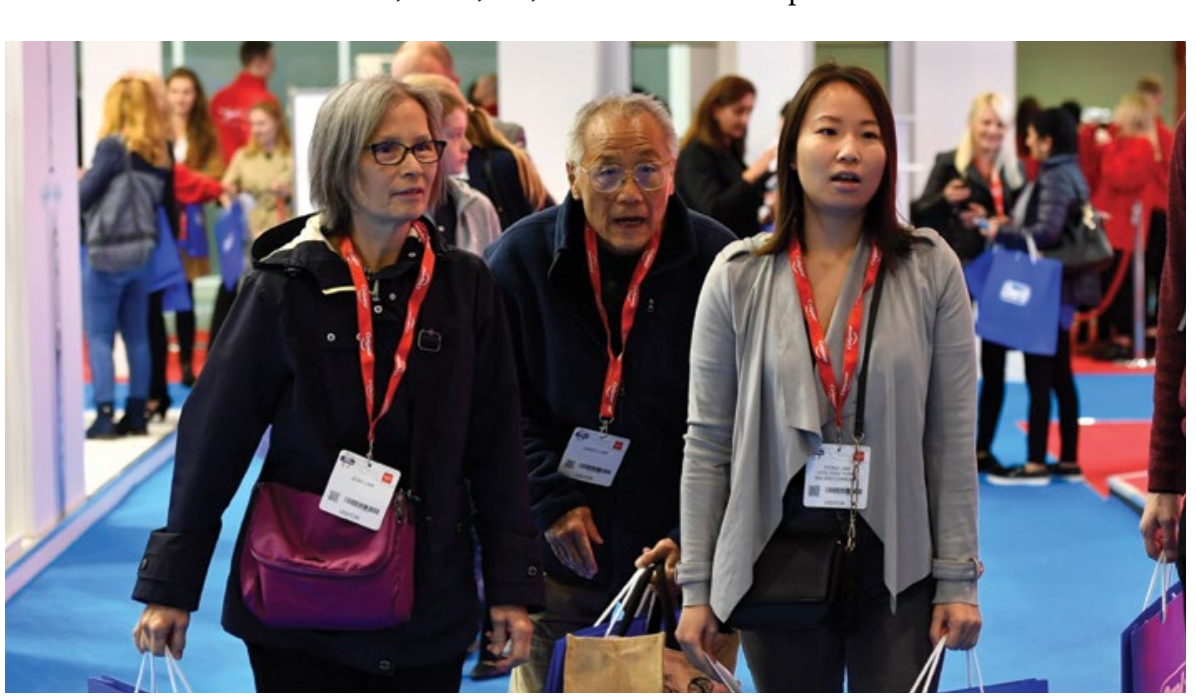

and 'play' with the products. Dental Showcase has more trade exhibitors than any other industry event. What's more, it takes place over three days so you can schedule the team's attendance, meaning no loss of business.

People attend Dental Showcase for different reasons, and although many are lured by the opportunity to look at what's available to buy, some come simply for the educational opportunities. This year's lecture programme has again been designed to be broad in its scope. Abdul Osman, a dental surgeon from Face Dental, will be looking at communication strategies and how they can impact both patient and team perspectives. He will also explore the popular concept of mindfulness within a dental setting, and how you can benefit by sensing the present rather than rehashing the past or trying to imagine the future.

The safeguarding of vulnerable adults is another example of a lecture relevant to all

\section{Build a positive dental experience for kids}

With children's oral health being such a key issue, practitioners must focus on providing a positive dental experience for their youngest patients.

Teaching children effective brushing techniques and explaining the importance of good oral hygiene not only helps to reduce their anxiety, it supports their future oral health too.

Demonstrate effective techniques with TANDEX brushes, which are high quality, functional and designed to give an efficient and gentle treatment for the smallest mouths.

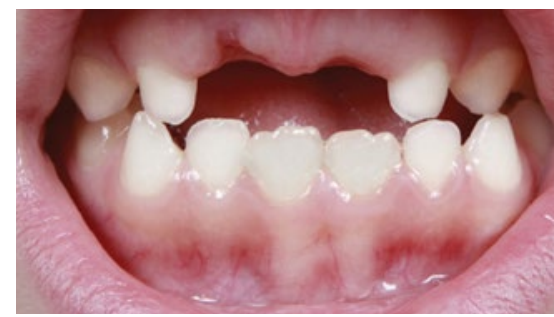

TANDEX brushes and adjunctive products are for life-long oral health - click now, to find out more about the range.

For more information on Tandex's range of products, visit www.tandex.dk. 